\title{
LA TEORÍA DE LA OBJETIVIDAD INTERNA EN EL ÁMBITO JURÍDICO
}

THE THEORY OF INTERNAL OBJECTIVITY IN THE LEGAL DOMAIN

BERNARDO ANDRÉs GALLEGOS MENDOZA ${ }^{1}$

Resumen, Este artículo aclara el concepto de objetividad jurídica interna. Destaca el papel que la Ley de Hume desempeña en esa teoría y presenta lo que llamo, la "extensión de la Ley de Hume": sólo se puede obstaculizar una proposición jurídica a través de una proposición evaluativa.

Palabras clave: Objetividad metafisica, objetividad interna, ley de Hume, escepticismo del error, escepticismo de estatus.

Aвstract: This paper clarifies the concept of internal legal objectivity. It highlights the role of Hume's Law in that theory and introduces that I call the "Hume's Law Extension": undermining a legal proposition requires an evaluative proposition.

Keywords: Metaphysical objectivity, internal objectivity, Hume's law, error skepticism, status skepticism.

Sumario: I. Introducción; II. La teoría de la objetividad metafísica en el ámbito evaluativo; III. La teoría de la objetividad interna en el ámbito moral; 1. La Ley de Hume; 2. La extensión de la ley de hume; 3. El rechazo del escepticismo externo de estatus; 4. El rechazo del escepticismo externo del error; IV; La teoría de la objetividad interna en el ámbito jurídico; V. Conclusiones; VI. Fuentes.

${ }^{1}$ Realizó estudios de Licenciatura en derecho y filosofía en la UNAM. Ha impartido las cátedras de Teoría Jurídica Contemporánea I y Lógica I en el Posgrado de Derecho de la UNAM. Actualmente es candidato a grado de Doctor por la Facultad de Filosofia y Letras de la UNAM a la cual se encuentra adscrito. < bernardogallegosm@ gmail.com>. ORCID: <https://orcid.org/0000-0002-8215-1755>.

Fecha de recepción: 19 de noviembre de 2019; fecha de aprobación: 31 de enero de 2020. 
I. I N TRODUCCIÓN

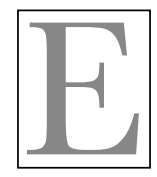
predicado "es objetivo" se utiliza para un amplio ámbito de sujetos gramaticales. Lo asociamos en ese sentido a afirmaciones, creencias, discursos, la realidad, procedimientos, clasificaciones, etc. Además de esto contamos con distintas perspectivas desde las cuales estudiar su concepto; tres de las más generales y aceptadas son la epistemológica, la semántica y la metafísica. ${ }^{2}$

La perspectiva epistemológica se enfoca en la justificación de nuestras creencias y la garantía que podemos ofrecer para ello; como lo hacemos, por ejemplo, al evitar prejuicios o factores personales. Desde esta perspectiva, pretendemos ser objetivos con el fin de que tendamos a una representación adecuada de las cosas y, para ello, se requiere que los procesos cognitivos sean confiables. Un proceso cognitivo no es confiable si el sujeto que lo realiza carece de información plena de los hechos relevantes, si está fuertemente influido por sus emociones, si piensa de antemano que debe llegar a cierta conclusión, etc. ${ }^{3}$

La perspectiva semántica, por otra parte, trata sobre la aptitud de los enunciados y afirmaciones para ser verdaderos o falsos. ${ }^{4}$ Los enunciados imperativos como “¡Cierra la puerta!”, carecen de esa

V., e.g., Coleman, Jules y Brian Leiter, "Determinacy, Objectivity, and Authority", University of Pennsylvania Law Review, núm. 142, 1993, pp. 594-607; Kramer, Matthew Objectivity and the Rule of Law, Cambridge, Cambridge University Press, 2007, cap. 1.

3 La objetividad epistemológica no siempre conduce a una representación adecuada de las cosas; sólo garantiza que a eso tienda, v., e.g., Raz, Joseph, "Notes on Value and Objectivity", en Brian Leiter (ed.), Objectivity in Law and Morals, Cambridge, Cambridge University Press, 2001, p. 198. Por otra parte, en el discurso jurídico la objetividad epistemológica se vincula también con la imparcialidad, v., e.g., Kramer Matthew, op., cit., pp. 53-64; cfr. Greenawalt, Kent, Law and Objectivity, Oxford, Oxford University Press, 1992, p. 121.

${ }^{4}$ V., e.g., Kramer, Matthew, Moral Realism as a Moral Doctrine, Oxford, Wiley-Blackwell, 2009, cap 8; Marmor, Andrei, Interpretación y Teoría del Derecho trad de Marcelo Mendoza, Barcelona, Gedisa, 2001, pp. 113-116; Raz, Joseph, op., cit., p. 197. aptitud y, por ende, no pueden ser objetivos desde el punto de vista semántico. No pueden ser verdaderos ni falsos, porque no describen nada del mundo. Otros enunciados como "Dios existe", independientemente de si son verdaderos o no, por el simple hecho de afirmar algo del mundo, poseen esa aptitud, y son objetivos desde este punto de vista. ${ }^{5}$

La perspectiva metafísica también se concentra en las afirmaciones, pero no por su aptitud para la verdad, sino por su corrección y fundamentación. Desde este punto de vista, una afirmación es objetiva sólo si es la respuesta correcta a una cuestión y su corrección se encuentra respaldada por algún hecho.

Estas tres perspectivas pueden mantener relaciones entre sí. Por ejemplo, desde el punto de vista de la objetividad metafísica se puede concluir escépticamente que ninguna afirmación moral es verdadera, porque desde el punto de vista semántico todas las afirmaciones de ese ámbito carecen de la aptitud para serlo. ${ }^{6}$ Sin embargo, las perspectivas no compiten entre sí; están explicando aspectos distintos de la objetividad.

Este artículo se encuentra acotado a un ámbito y una perspectiva muy específica. Su ámbito es el de las afirmaciones evaluativas, especialmente las jurídicas, y su perspectiva compite con la metafísica. Se trata de la perspectiva interna de la objetividad evaluativa. De la misma manera que la perspectiva metafísica, la interna también pretende explicar la objetividad de una afirmación desde

${ }^{5}$ Marmor, Andrei, op., cit., pp. 113-114. La objetividad semántica suele vincularse con el cognitivismo debido a que la capacidad de un enunciado para ser verdadero o falso es requisito indispensable para que sea cognoscible, v., e.g., Raz, Joseph, op., cit., p. 197. Los discursos evaluativos que son tomados recurrentemente como ejemplos de discusiones cognoscitivistas son la ética y la estética. Esto se debe a que se piensa que, en lugar de afirmar cómo son las cosas, podrían expresar (independientemente de su gramática superficial) sentimientos o actitudes.

${ }^{6}$ Esta posición, conocida como teoría del error, se le atribuye a Mackie, John, Ethics: Inventing Right and Wrong, Londres, Penguin Books, 1977, cap. I. Actualmente, Richard Joyce es un destacado defensor de esta teoría, v. The Myth of Morality, Cambridge, Cambridge University Press, 2001. Más adelante volveré sobre ella (v. infra, sec. III, subsec. 4). 
el punto de vista de su corrección y fundamentación; mantiene incluso que una afirmación es objetiva sólo si es la respuesta correcta a una cuestión, pero se opone a la perspectiva metafísica al afirmar que tal corrección no depende de ningún hecho, sino de la argumentación (en este sentido, puede interpretarse como una perspectiva antimetafísica)

El artículo estará enfocado en exponer la perspectiva interna de la objetividad jurídica a través de una de las mejores defensas que se han ofrecido a su favor; a saber, la que aporta el filósofo norteamericano Ronald Dworkin. ${ }^{7}$ Reconstruiré los trazos generales de tal defensa con la intención de mostrar la seria posibilidad de que sea la teoría correcta de la objetividad interna en el ámbito evaluativo; y, aunado a ello, destacaré dos de sus principales suposiciones: 1) la Ley de Hume; y, 2) lo que llamaré "la extensión de la Ley de Hume"; mismas que servirán para aclararnos su concepto.

Para entender qué se pretende sustituir con la teoría de la objetividad interna será conveniente ofrecer una caracterización general de la teoría de la objetividad metafísica.

II. LA TEORía de LA OBJetividad METAfísica en EL ÁmBito EVALUATIVO

La objetividad metafísica tiene como punto de partida la tesis de que existe un mundo externo capaz de fundar la verdad de cualquier proposición. Una manera de definirla es la siguiente: un enunciado es objetivo metafísicamente si y sólo si existe el objeto referido por el enunciado; y, un enunciado es objetivamente verdadero si y sólo si el objeto referido tiene las propiedades atribuidas. ${ }^{8}$ Supongamos que se afirma, "el mercurio es un metal". Este enunciado es objeti-

Otra influyente versión de teoría de la objetividad interna, aunque exclusiva para el ámbito moral es la que ofrece Kramer, Matthew (Moral Realism ..., cit.). En algunas partes del artículo discutiré sus afirmaciones.

${ }^{8}$ Marmor, Andrei, op., cit., p. 116 vo si y sólo si existe el mercurio. Es objetivamente verdadero si existe el mercurio y tiene la propiedad de ser metal; y, es objetivamente falso si existe el mercurio, pero no tiene la propiedad atribuida.

En la literatura especializada la objetividad metafísica se clasifica de dos maneras. Por la medida en que la se exige independencia mental se clasifica en objetividad fuerte, modesta y débil. ${ }^{9}$ Por su naturalización se clasifica en naturalista y no naturalista. ${ }^{10}$

La independencia mental fuerte se basa en que el objeto referido en un enunciado exista en una realidad independiente de las actitudes y creencias de la gente, ya sean particulares o colectivas. Sólo los enunciados referidos a esas realidades pueden ser verdaderos o falsos. ${ }^{11}$

${ }^{9}$ V., e.g., Coleman, Jules y Brian Leiter, op., cit., pp. 601-632; Coleman, Jules, "Truth and Objectivity in Law", Legal Theory, vol. 1, núm. 1, 1995, p. 56; Leiter, Brian, Naturalizing furisprudence: Essays on American Legal Realism and Naturalism in Legal Philosophy, Oxford, Oxford University Press, 2007, pp. 259-261 [trad. esp.: 2012, pp. 329-333]; cfr. Kramer, Matthew, Objectivity ..., cit., pp. 3-14.

${ }^{10}$ V., e.g., Leiter, Brian, op., cit., 239-255 [trad. esp.: 2012, pp. 310-327]; Street, Sharon, "Objectivity and Truth: You'd Better Rethink it", en Russ Shafer-Landau (ed.), Oxford Studies in Metaethics, vol. 11, Oxford, Oxford University Press, 2016, pp. 299-300.

1 Para un esbozo de este tipo de objetividad fuerte en el derecho, $v$. Alexander, Larry, "Legal Objectivity and the Illusion of Legal Principles", en Matthias Klatt (ed.), Institutionalized Reason: Thefurisprudence of Robert Alexy, Nueva York, Oxford University Press, 2012, pp. 123-129. Uno de los más destacados defensores en este ámbito es el iusnaturalista Michael Moore, quien defiende que el derecho es un objeto de tipo funcional, v., "Semantics, Metaphysics and Objectivity in the Law", en Geert Keil y Ralf Poscher (eds.), Vagueness and Law, Nueva York, Oxford University Press, 2016, pp. 127-157.

Es pertinente observar que las teorías de la objetividad jurídica y moral de Dworkin podrían implicar algunas características del realismo: i) su teoría del derecho implica un tipo de realismo semántico, v. Ibidem, p. 139; Stavropoulos, Nicos, Objectivity in Law, Oxford, Oxford University Press, 1996, pp. 129-136, 160; cfr. Dworkin, Ronald, fustice in Robes, Cambridge, Massachusetts, Harvard University Press, 2006, cap. VI; ii) su teoría moral es un «realismo relajado» ya que, aun cuando niegue que las verdades morales tengan implicaciones ontológicas positivas el hecho es que hay verdades morales, v. Cuneo, Terence y Russ Shafer-Landau, "The Moral Fixed Points, New 
La independencia mental modesta se ha ofrecido como una respuesta al problema de la verdad derivado de nuestra inaccesibilidad referencial al mundo como es en sí mismo. ${ }^{12}$ Según esta independencia, la objetividad está fundada en sujetos bajo condiciones epistémicas ideales: "Algo es modestamente objetivo si su existencia y naturaleza dependen solamente de lo que los sujetos cognitivos creerían bajo ciertas condiciones ideales de conocimiento, como información plena, pruebas exhaustivas, racionalidad perfecta, etc.". ${ }^{13}$

Lo atractivo de la independencia mental fuerte y la modesta es que ambas suponen superar, a su modo, la dificultad de la infalibilidad. La fuerte porque hace depender la objetividad de la realidad y la modesta porque incluye condiciones epistémicas ideales que funcionan como límite para las creencias de individuos e incluso de una colectividad. ${ }^{14}$

Directions for Moral Nonnaturalism", Philosophical Studies, núm. 171, 2014, p. 400 o, desde otro punto de vista, aun cuando niegue que la existencia de propiedades y verdades morales tengan un rol en la explicación de por qué creemos estas últimas, supone que existen despreocupadamente, $v$. McGrath, Sarah, "Relax? Don't Do It! Why Moral Realism Won't Come Cheap”, en Russ Shafer-Landau (ed.), Oxford Studies in Metaethics, vol. 9, Oxford, Oxford University Press, 2014, p. 186; y iii) se basa en una independencia mental fuerte de las verdades jurídicas y, en opinión de algunos, esa es la marca del realismo, v. Patterson, Dennis, Law and Truth, Oxford, Oxford University Press, 1996, p. 8. En la siguiente sección veremos que aun cuando estas observaciones fueran correctas sería un error llegar a concluir de ello una tesis de objetividad metafísica en las teorías moral y jurídica de Dworkin.

${ }^{12}$ Para la explicación de este problema en el ámbito jurídico, v. Coleman, Jules, op., cit., pp. 40-42.

${ }^{13}$ Leiter, Brian, op., cit., p. 260 [trad. esp.: 2012, p. 333]. En el derecho la defensa más representativa de este tipo de objetividad puede atribuirse a Coleman, Jules y Brian Leiter, op., cit., pp. 612-632. Aplicada a este ámbito, la caracterizan como sigue: «Sólo lo que parece correcto a individuos colocados en una posición epistémicamente ideal determina lo que es correcto» (p. 621; la traducción es mía).

${ }^{14}$ La objetividad modesta no acaba por completo el problema de la infalibilidad, pues queda desplazada ahora a este último tipo de sujetos; es decir, aún serían infalibles las creencias producto de las condiciones ideales. Para algunas críticas en contra de la objetividad modesta, v. Schiavello, Aldo, "The Third Theory of Legal Objectivi-
Finalmente, la independencia mental débil mantiene que la objetividad metafísica se presenta cuando, al separar creencias y actitudes particulares, de las compartidas por la mayoría de los miembros de un grupo, la verdad de un enunciado está apoyada por estas últimas. ${ }^{15}$ La infalibilidad es uno de los problemas más serios para esta objetividad mínima. Esto se debe a que parece aceptable pensar que la mayoría puede tener creencias y actitudes equivocadas. ${ }^{16}$

Desde la segunda clasificación la objetividad metafísica puede ser naturalista o no naturalista. Tanto la objetividad fuerte, como la modesta y la débil, pueden apelar a hechos naturales (i.e., aquellos que tienen eficacia causal como los físicos) como a hechos no naturales (i.e., aquellos que carecen de eficacia causal como los evaluativos). De conformidad con estas apelaciones se podrán clasificar como teorías naturalistas o no naturalistas.

Lo que tienen en común todas estas propuestas sobre la objetividad metafísica es su capacidad de explicar, a través de hechos, cómo es que puede haber, al menos en algunas ocasiones, respuestas correctas y únicas en ámbitos evaluativos. Por ejemplo, en el ámbito jurídico mantienen que ciertas proposiciones jurídicas son las respuestas correctas y únicas para ciertos casos, dado que, en alguno de los sentidos descritos, hay objetos y hechos independientes de la mente que las hacen verdaderas.

ty", en M. Araszkiewicz y J. Savelka (eds.), Coherence: Insight from Philosophy, Furisprudence and Artificial Intelligence, Dordrecht, Springer, 2013, pp. 146-153.

${ }^{15}$ Un destacado defensor de esta postura es Marmor. Define que asuntos como la inflación, el ajedrez y el límite de velocidad tienen referentes que «no pueden ser concebidos como ontológicamente independientes de nuestro conocimiento y cultura» (op., cit., p. 118; la traducción es mía) y, sin embargo, son metafísicamente objetivos.

${ }^{6}$ En Kramer, Matthew, Objectivity ..., cit., p. 9 se puede encontrar una posible respuesta a este problema. Para otra, $c f r$. Marmor, Andrei, op., cit., p. 138. 
III. LA TEORía de LA OBJetividad INTERNA EN EL ÁMBITO MORAL

Como ya se ha anunciado la objetividad que será tratada en este artículo es la interna y en particular la del ámbito jurídico. Dworkin, el teórico en el que me basaré, propuso una teoría de la objetividad interna no sólo para el dominio jurídico, sino para todo dominio donde formulamos juicios de valor, i.e., la estética, la moral, la interpretación, etc. ${ }^{17}$ Dworkin, sin embargo, desarrolló su teoría utilizando al ámbito moral como su preferido. ${ }^{18}$ Sugirió que la misma teoría adaptada a los otros ámbitos evaluativos funcionaría de manera paralela. En este sentido, el núcleo del artículo se desarrollará dentro del ámbito moral y en una sección posterior se expondrá su adaptación al ámbito jurídico.

1. LA Ley de Hume

Bajo la aclaración anterior, debe comenzarse por señalar que, de acuerdo con la teoría moral de Dworkin, el espacio conceptual de la objetividad interna en el ámbito moral es el siguiente: todas las verdades morales se mantienen con independencia de las creencias y actitudes de la gente, pero sus fundamentos no son meramente hechos naturales, ni supuestos hechos morales, sino la argumentación moral adecuada. ${ }^{19}$

${ }^{17}$ V. Dworkin, Ronald, fustice for Hedgehogs, Cambridge, Massachusetts, Harvard University Press, 2011.

${ }^{18}$ V. Dworkin, Ronald, "Objectivity and Truth, You'd Better Believe it", Philosophy and Public Affairs, vol. 25, núm. 2, 1996, pp. 87-139; Justice in Robes, Cambridge, Massachusetts, Harvard University Press, 2006; fustice for ..., cit.

${ }^{19}$ Para los presentes propósitos no será necesario desarrollar la teoría correcta sobre una argumentación moral adecuada, pues basta con suponer que alguna lo es. Dicho apretadamente, Dworkin mantuvo que el razonamiento moral es una forma de razonamiento interpretativo (v. Justice for ..., cit., pp. $38-39$ [trad. esp.: 2014, p. 59]), de modo que la argumentación moral adecuada es interpretativa.
La defensa de este espacio conceptual está basada en dos tesis centrales. La menos controvertida de ambas es la siguiente:

1) " $[\mathrm{L}]$ os juicios morales son verdaderos, cuando lo son, por obra de un argumento moral adecuado a favor de su verdad.”20

El apoyo a favor de la verdad de esta tesis parte de la observación de que los hechos naturales no podrían ser el fundamento completo de las verdades morales porque eso supondría que nuestras afirmaciones sobre los primeros implicarían afirmaciones sobre las segundas; lo cual transgrediría la Ley de Hume. Esta Ley suele extraerse del pasaje siguiente:

En todo sistema moral de que haya tenido noticia, hasta ahora, he podido siempre observar que el autor sigue durante cierto tiempo el modo de hablar ordinario, estableciendo la existencia de Dios o realizando observaciones sobre los quehaceres humanos y, de pronto, me encuentro con la sorpresa de que, en vez de las cópulas habituales de las proposiciones: es y no es, no veo ninguna proposición que no esté conectada con un debe o un no debe. Este cambio es imperceptible, pero resulta, sin embargo, de la mayor importancia. En efecto, en cuanto que este debe o no debe expresa alguna nueva relación o afirmación, es necesario que ésta sea observada y explicada y que al mismo tiempo se dé razón de algo que parece absolutamente inconcebible, a saber: cómo es posible que esta nueva relación se deduzca de otras totalmente diferentes. ${ }^{21}$

De conformidad con la cita, Hume afirma que ningún conjunto de enunciados descriptivos puede implicar alguno evaluativo. Por ello, la mera descripción de hechos naturales no podría implicar una afirmación moral. ${ }^{22}$ Nótese que esto no significa que un hecho

${ }^{20}$ Ibidem, p. 37 [trad. esp.: 2014, p. 57].

${ }^{21}$ Hume, David, Tratado de la Naturaleza Humana, trad. de Félix Duque, Madrid, Tecnos, 2005, pp. 633-634.

${ }_{22}^{2}$ Dworkin consideraba patentemente verdadera la Ley de Hume, v. fustice for .... cit., p. 44 [trad. esp.: 2014, p. 65]. 
natural nunca pueda ser parte del fundamento de una verdad moral; si, por ejemplo, alguien daña físicamente a otra persona, ese hecho natural puede ser parte del fundamento de la verdad moral de que debe resarcirla. La Ley de Hume se cumple al suponer la norma moral de que todo daño debe ser indemnizado. Este es el tipo de argumentación moral que exige la teoría de la objetividad interna, incluso para las afirmaciones del nivel más abstracto de la moral.

Por otra parte, la mera descripción de supuestos hechos morales tampoco podría fundar una afirmación moral. Dworkin afirma, "[n] adie que sostiene que la esclavitud es 'realmente' incorrecta piensa que con ello ha dado, o incluso sugerido, un argumento de por qué lo es. (¿Cómo podrían las vibraciones o las entidades nouménas proporcionar cualquier argumento para las convicciones morales?). ${ }^{23}$ La razón de esta afirmación es la siguiente.

Si interpretamos que nuestra descripción de la existencia de los hechos morales es una afirmación metafísica, entonces al igual que con la propuesta de los hechos naturales se transgrede la Ley de Hume: pretenderíamos que de una afirmación metafísica (descriptiva) se pueda deducir una moral. Y, por otra parte, si interpretamos que nuestra descripción de la existencia de hechos morales no expresa en realidad una afirmación metafísica, sino una moral, entonces no se transgrede la Ley de Hume, pero tampoco ejemplifica ninguna tesis de objetividad externa o metafísica, sino un argumento moral circular, porque sólo estaríamos diciendo que la esclavitud es incorrecta, porque la esclavitud es incorrecta, lo cual no explica nada.

A esto último se puede agregar que la tesis metafísica de que hay hechos morales es absurda porque en el discurso moral y en el jurídico suponemos que hemos tenido contacto con los fundamentos de sus verdades. Es decir, si los fundamentos de la verdad evaluativa

${ }^{3}$ Dworkin, Ronald, Law's Empire, Cambridge, Massachusetts, Harvard University Press, 1986, p. 81 [trad. esp.: 1992, pp. 67-68]. fueran hechos evaluativos entonces estaríamos suponiendo que hemos tenido contacto con ellos, pero como es inexplicable que tengamos contacto con hechos que carecen de eficacia causal, se sigue que la suposición es falsa y, en consecuencia, la verdad evaluativa no puede estar fundada en hechos evaluativos.

La Ley de Hume, en consecuencia, es el apoyo esencial para sostener que existe un espacio conceptual de acuerdo con el cual toda verdad moral deriva de algún argumento moral adecuado. Sin embargo, este espacio conceptual está sujeto a una buena objeción: si pudiera mostrarse que la verdad moral puede obstaculizarse sin apelar a argumentación evaluativa alguna, su posibilidad conceptual se desacreditaría, porque finalmente la argumentación moral adecuada no sería suficiente para establecer las verdades de sus respectivos ámbitos.

Dworkin ofrece un valioso análisis al respecto. Explica que existen dos desafíos generales a la verdad de los juicios morales: el escepticismo interno y el externo. En su opinión, una teoría escéptica interna es una teoría moral, no metafísica. Se distingue por rechazar juicios morales positivos ${ }^{24}$ sin austeridad y sin neutralidad. Que una teoría moral escéptica sea austera significa que sus juicios escépticos pueden fundarse sin apelar a juicios morales positivos y que sea neutral significa que sus juicios escépticos no tienen consecuencias directas para la acción. ${ }^{25}$ El escepticismo moral interno entonces basa sus juicios escépticos en juicios morales positivos y mantiene consecuencias directas para la acción.

\footnotetext{
${ }^{24}$ Según Dworkin un juicio moral positivo adscribe un predicado moral a un acto, o persona, o acontecimiento; uno negativo niega tal adscripción [...]. La clase de los juicios morales positivos incluye [...] también formas más complejas de tal adscripción, incluyendo aquellas de tipo condicional [...] y las de tipo contrafactual [...]. Incluye también afirmaciones acerca de la moralidad como un todo que implican o presuponen adscripciones directas, condicionales o contrafactuales de propiedades evaluativas. (“Objectivity ...", cit., p. 90 [trad. esp.: 2009, pp. 20-21]. Dworkin entendía los juicios morales permisivos como positivos, v. Ibidem, p. 129 [trad. esp.: 2009, p. 76].

${ }^{25}$ V. Ibidem, pp. 90-92 [trad. esp.: 2009, pp. 21-23]
} 
Este tipo de escepticismo puede ser parcial o global. Lo primero ocurre cuando rechaza un grupo de afirmaciones morales positivas concernientes a un ámbito de la conducta; por ejemplo, la del autodaño. Si se mantiene que la moral sólo es una cuestión de nuestras relaciones con los otros, las afirmaciones morales sobre la corrección o incorrección del autodaño no serán verdaderas ni falsas. Lo segundo, en cambio, se presenta cuando rechaza todos los juicios morales positivos (o, al menos, los positivos atómicos). Puede afirmarse, por ejemplo, que nadie puede llegar a tener un deber moral en ningún sentido. Esto es escepticismo global; sin embargo, por su falta de austeridad, se ha de fundar en algún juicio moral, por ejemplo, que si hubiera una voluntad divina habría deberes morales (agregando que dicha voluntad no existe). ${ }^{26}$

De la explicación de Dworkin se sigue que las teorías escépticas internas de la moral no desafían la teoría de la objetividad interna; al contrario, son ejemplos posibles de ella, porque de ser correcta alguna de aquellas, sus juicios escépticos estarían fundados en argumentación moral adecuada.

El escepticismo moral externo, también llamado arquimediano, está caracterizado por su austeridad. En el ámbito moral Dworkin discute dos vertientes de esta teoría. La primera es la del escepticismo moral externo del estatus, la cual rechaza todos los juicios morales positivos con base en un juicio o conjunto de juicios metafísicos o metaéticos (austeridad), pero agrega neutralidad al afirmar que ello no tiene implicaciones directas para la acción. ${ }^{27} \mathrm{El}$ segundo es el escepticismo moral externo del error que rechaza igualmente todos los juicios morales positivos, también a través de una afirmación o conjunto de afirmaciones austeras, pero niega la neutralidad,

${ }^{26}$ Como se observa el escepticismo global no es, lo que en adelante llamaré "escepticismo total". Éste último requiere obstaculizar todos los juicios morales no sólo los positivos.

${ }^{27}$ V. Dworkin, Ronald, “Objectivity ...”, cit., p. 92 [trad. esp.: 2009, pp. 23-24]. al afirmar que tiene implicaciones directas para la acción. ${ }^{28}$

Cualquiera de las versiones del escepticismo externo evade las dos grandes objeciones mencionadas a los desafíos que representan las teorías de la objetividad externa (la Ley de Hume y la absurda tesis de los hechos morales). La Ley de Hume sólo exige que para deducir una proposición evaluativa se tenga que partir de alguna premisa evaluativa; pero no exige que para deducir una conclusión obstaculizadora de una proposición evaluativa (por ejemplo, que no es verdadero ni falso que el autodaño esté prohibido) se requiera alguna premisa evaluativa; de modo, que el escepticismo externo, que sólo busca obstaculizar, es compatible con la Ley de Hume. La tesis metafísica de los hechos morales, por otra parte, afirma que estos últimos existen; el escepticismo externo lo niega (o al menos es compatible con dicha negación) y, por consiguiente, no es vulnerable a la objeción de absurdez.

El escepticismo externo, en consecuencia, puede desacreditar la teoría de la objetividad interna en el ámbito moral (y por extensión en el jurídico). Ello hace necesario una defensa de la posibilidad de esta última teoría en los términos de la tesis siguiente:

2) "Los desafíos filosóficos a la verdad de los juicios morales [las teorías escépticas de la moral] son en sí mismos teorías morales sustantivas." 29

Parte importante de la defensa de esta última afirmación se basa en una sutil distinción de tres tipos de juicios obstaculizadores de la verdad moral. Dos de ellos internos:

${ }^{28}$ V. Ibidem, pp., 112-113 [trad. esp.: 2009, p. 52]. A partir de cómo concibe Dworkin los tipos de escepticismo moral, se sigue que sólo el escepticismo moral externo es conceptualmente capaz de ser total. Se debe observar además que el escepticismo moral del estatus conceptualmente sólo tiene la capacidad de ser externo. «No hay escepticismo interno del estatus» dice Dworkin (v. Fustice for ..., cit., p. 33 [trad. esp.: 2014, p. 53]. De ello se sigue que sólo podría ser total; es decir, el escepticismo moral externo del estatus conceptualmente sólo tiene la capacidad de ser total.

${ }^{29}$ Ibidem, p. 34 [trad. esp.: 2014, p. 54]. 
Supongamos que estalla una discusión acerca del aborto en circunstancias particulares - digamos, cuando se ha diagnosticado una seria anormalidad fetal. Un bando insiste en que el aborto está prohibido en estas circunstancias, y el otro en que resulta obligatorio. Por supuesto, hay una tercera alternativa: es permisible pero no obligatorio. Esta alternativa es neutral como entre los contrincantes originales, pero no es neutral en la discusión que están teniendo. Toma una posición - sostiene que ambas están equivocadas- y tiene una implicación directa para la acción porque afirma que sería un error interferir con una decisión de aborto, en cada caso, sobre fundamentos morales. Supongamos ahora un cuarto bando, que insiste en que las tres visiones están erradas porque los juicios morales no pueden ser verdaderos o falsos, o porque no hay propiedades morales, o sobre la base de algún otro fundamento arquimédico. Esta cuarta visión tampoco es neutral. Insiste en que es un error tanto el exigir como el oponernos a un aborto sobre bases morales. Por eso, tiene las mismas implicaciones para la acción que la tercera visión, y si bien está expresada en un lenguaje más ambiguo, no es más neutral. ${ }^{30}$

De conformidad con este pasaje, tanto las afirmaciones permisivas como los juicios de indeterminación moral son juicios escépticos internos. Un juicio permisivo es la negación lógica de un juicio de prohibición; por ejemplo, sostener que el aborto puede deónticamente efectuarse equivale a negar que el aborto debe evitarse. ${ }^{31}$ Por lo que respecta a las proposiciones de indeterminación moral entenderé, igualmente de conformidad con Dworkin, que de alguna forma hacen una "negación general de todas las proposiciones positivas aparentemente elegibles." ${ }_{32}$ Entre otros ejemplos se encuentra aquel que niega tanto la verdad como la falsedad de una proposición moral, por ejemplo, al mantener que "debe hacerse $\phi$ " no es verdadero ni falso.

${ }^{30}$ Dworkin, Ronald, “Objectivity ...”, cit., pp. $94-95$ [trad. esp.: 2009, p. 27].

${ }^{31}$ Se puede deducir el asentimiento que Dworkin habría tenido al respecto en $i b i$ dem, p. 129 [trad. esp.: 2009, p. 76].

$$
{ }^{32} \text { Idem. }
$$

Según la explicación de Dworkin, ambos tipos de proposiciones tienen una interpretación moral porque coinciden en las mismas implicaciones directas para la acción. Contrario a lo que pueda parecer, éstas no consisten en deberes morales de no interferencia o de abstención a la crítica, sobre bases morales ${ }^{33}$ sino en los juicios morales contrafácticos que suponen: tantos los juicios permisivos como los de indeterminación moral suponen que, si hubiera ciertos hechos o razones morales, alguien tendría un deber moral. Este último tipo de juicio es moral y por la Ley de Hume no pudo haber sido deducido de alguno no moral. Pero, como está supuesto en un juicio permisivo o de indeterminación moral, se sigue que estos últimos juicios tienen que ser morales. ${ }^{34}$

Así, si la teoría de la objetividad interna está sujeta a alguna objeción por la manera en que pueden obstaculizarse los juicios morales, tiene que haber algún tipo de indeterminación de otra categoría, una que muestre que podemos decir que los juicios morales no son verdaderos ni falsos en un sentido extraordinario, una que no contenga implicaciones directas para la acción (es decir, que ni

${ }^{33} \mathrm{El}$ error que cometeríamos si, sobre bases morales, criticásemos una conducta permitida o indeterminada moralmente, no sería moral; sino al parecer uno de coherencia, porque estaríamos criticando, sobre bases morales, una conducta que ya suponemos no tiene bases morales para ser criticada. Por lo que respecta al asunto de poder o no interferir, sobre bases morales, en una conducta permitida o indeterminada moralmente, no hay nada incoherente en poder hacerlo. Un jugador puede tener permitido lograr un tanto y eso no significa que los jugadores del equipo contrario tengan el deber de no interferir. Al parecer Dworkin estuvo de acuerdo con estos puntos de vista, $v$. Marti, Jose Luis y Hugo Omar Seleme, "Dworkin on external skepticism and moral permissions", Critical Review of International Social and Political Philosophy, vol. 19, núm. 4, 2016, p. 12.

${ }^{34}$ Sobre la calidad moral de los juicios permisivos, $v$. también Kramer, Matthew, Moral Realism ..., cit., pp. 20-21. La tesis de que las afirmaciones de indeterminación moral son morales (internas al ámbito moral) seguramente resultará sorprendente para el lector. Por el momento sólo destacaré que es distinguible de un tercer tipo de juicio obstaculizador de la verdad moral (que en breve describiré) que también tiene que ser descartado por la defensa de la teoría moral de la objetividad interna. 
siquiera implique juicios morales teóricos o contrafácticos). Se trata de aquello que pretendemos expresar a través de un tercer tipo de juicio obstaculizador de la verdad moral y cuyo sentido sería externo. A los juicios que pertenecen a este tercer tipo los llamaré "juicios externos de indeterminación". Seguramente Dworkin se refería a ellos al concebir la posibilidad del escepticismo externo:

Si lo arquimédico es mostrar que este tipo de escepticismo realmente es neutral, debe hacer más que simplemente apuntar al espacio lógico entre los juicios de obligación y prohibición, o recordarnos que decir que una proposición no es ni verdadera ni falsa es diferente de decir que es falsa. Necesita más estructura y un argumento más ambicioso que ése.

Debe mostrar que el objetivo de esta crítica es algo del todo distinto de las afirmaciones morales sustantivas habituales que todos hacemos de modo que podamos aceptar sus argumentos mientras continuamos juzgando y actuando, en la dimensión moral, como lo hicimos antes. ${ }^{35}$

Es este último tipo de juicio y escepticismo el realmente preocupante para la teoría de la objetividad interna. La Ley de Hume no contiene ningún pronunciamiento sobre su carácter moral. La respuesta más bien depende de la verdad o falsedad del escepticismo moral externo. Si el escepticismo moral externo es falso o está mal concebido se seguirá que todo tipo de juicio obstaculizador de las verdades morales es moral y ello implicará que se podría extender la Ley de Hume en el sentido siguiente: ninguna afirmación obstaculizadora de un juicio moral puede ser deducida de meras premisas descriptivas (en adelante, "la extensión de la Ley de Hume").

\footnotetext{
${ }^{35}$ Dworkin, Ronald, “Objectivity ...”, cit., p. 95 [trad. esp.: 2009, pp. 27-28].
}

\section{LA EXTENSIÓN DE LA LEY DE HUME}

Antes de avanzar realizaré un par de observaciones sobre la extensión de la Ley de Hume que nos evitarán malentendidos. La primera es que dicha extensión no la deduce Dworkin del deflacionismo de la verdad y la segunda es que tampoco es una premisa que Dworkin utilice para probar que el escepticismo externo es falso, sino, como se ha mencionado, es lo contrario: utiliza la falsedad del escepticismo externo como premisa para concluir la extensión de la Ley de Hume.

La primera observación la hago en atención a la defensa del realismo moral como doctrina moral de Mathew Kramer. ${ }^{36}$ Este autor es otro renombrado defensor de la tesis de la objetividad interna en el ámbito moral. Afirma (como más adelante veremos que Dworkin también sostiene) que no hay una sola tesis metaética que sea completamente neutral respecto al ámbito ético, ${ }^{37}$ agregando que el discurso metaético debería ser reconsiderado como un tipo de discurso ético cuya distinción radica en los problemas a los cuales se dirige ${ }^{38} \mathrm{o}$ en su manera de resolverlos. ${ }^{39} \mathrm{El}$ argumento principal que este autor desarrolla para apoyar estas afirmaciones está basado en la observación de que diversas defensas de neutralidad de tesis metaéticas fracasan. ${ }^{40}$ Pero también mantiene que la teoría adecuada

${ }^{36}$ V. Moral Realism ..., cit.

${ }^{37}$ Ibidem, esp. cap. 10.

${ }^{38}$ Ibidem, p. 5.

${ }^{39}$ Kramer, Matthew, "There's Nothing Quasi About Quasi-Realism: Moral Realism as a Moral Doctrine", University of Cambridge Faculty of Law Research Paper, núm. 42, 2016, pp. 38-39.

${ }^{40}$ Estudia a detalle, por ejemplo, las tesis de Hare, Blackburn y Shafer-Landau, respecto de la superveniencia de las propiedades éticas sobre las naturales (y que para esos autores son tesis lógicas o metafísicas), llegando a la conclusión de que ese tipo de tesis de superveniencia son éticas, v. Moral Realism ..., cit., cap. 10. También es de especial importancia su observación (v. ibidem, pp. 36-38) sobre la falta de neutralidad de la tesis metaética que en Dreier ("Meta-ethics and Normative Commitment", Phi- 
de la verdad moral es el minimalismo; ${ }^{41}$ una teoría deflacionaria de la verdad. ${ }^{42}$

El deflacionismo de la verdad mantiene que la verdad no es una propiedad (deflacionismo fuerte) o, en su caso, no es una propiedad sustantiva u ordinaria (deflacionismo débil) y, por tanto, las palabras "es verdadero" no agregan nada a una proposición. Mantiene que dos proposiciones son equivalentes si únicamente se diferencian en que una agrega "es verdadero" en tanto que la otra no. Por ejemplo, sostener que el mercurio es un metal es equivalente a sostener que es verdadero que el mercurio es un metal. ${ }^{43}$ De modo que la naturaleza de la verdad se explica por el esquema siguiente:

$>$ La proposición " $P$ " es verdadera si y sólo si $P$.

Guya ejemplificación en el ámbito moral sería la siguiente: "Todos los actos de tortura a bebés por placer están moralmente prohibidos" es verdadero si y sólo si todos los actos de tortura a bebés por

losophical Issues, núm. 12, 2002, p. 259) se propone como neutral.

${ }^{41}$ V. Kramer Matthew, Moral Realism ..., cit., pp. 261-264; "Working on the Inside: Ronald Dworkin's Moral Philosophy”, Analysis Revieres, vol. 73, núm. 1, 2013, p. 121 "There's Nothing ...", cit., pp. 35-37.

${ }^{42}$ Para un punto de vista concordante, v. Hanin, Mark, "Ethical Anti-Archimedeanism and Moral Error Theory", fournal of Value Inquiry 47, núm. 4, 2013, pp. 367368. Aunque Kramer (Moral Realism ..., cit., p. 261) excluye enunciados declarativos que carezcan de valores de verdad por ser paradójicos, contener alguna falla de presuposición o que aplican predicados vagos a casos fronterizos, parece hacerlo sólo para fines expositivos, pues sugiere que el minimalismo puede dar cuenta de ellos.

$\mathrm{N}$ o investigaré la inconsistencia ostensible entre la explicación minimalista de la verdad y la afirmación de que algunos enunciados morales declarativos significativos carecen de valores de verdad. En general, apoyo el tratamiento de Holton para resolver esa inconsistencia putativa, aunque favorezco una no-Lukasiewicziana variante de este tratamiento. Elaborar dicha variante, sin embargo, me llevaría demasiado lejos en este capítulo; en su lugar llevaré a cabo la tarea en un artículo separado. (Ibidem, p. 265, n. 5; la traducción es mía).

${ }^{43}$ Para una recomendable introducción y sondeo sobre el deflacionismo de la verdad y sus versiones, v. García Suárez, Alfonso, Modos de Significar, 2a. ed., Tecnos, Madrid, 2011, cap. 7. placer están moralmente prohibidos. Por otra parte, la naturaleza de la falsedad se explica por el siguiente esquema:

$>$ La proposición " $P$ " es falsa si y sólo si no $P$.

Misma que, en el ámbito moral, podemos instanciar con: "Todos los actos de tortura a bebés por placer son moralmente permisibles" es falso si y sólo si no es el caso que todos los actos de tortura a bebés por placer son moralmente permisibles.

Del minimalismo de Kramer se siguen las dos tesis siguientes:

- La proposición " $P$ " no es verdadera si y sólo si no $P$

- La proposición " $P$ " no es falsa si y sólo si $P$.

Esto nos mostraría que las afirmaciones que niegan la verdad de una proposición moral implican la negación de dicha proposición moral. Según este análisis, que no sea verdadero que cierta persona debe evitar abortar implica la negación de que dicha persona debe evitar abortar (i.e., que puede deónticamente abortar).

De lo anterior se sigue que negar que sea verdadero que cierta persona debe evitar abortar es una afirmación moral. La plausible extensión de este análisis a todas las afirmaciones que niegan la verdad de una afirmación moral podría explicar la extensión de la Ley de Hume: si las proposiciones que niegan verdades morales son proposiciones morales, entonces, basta la Ley de Hume para reconocer que no se puede deducir la negación de una verdad moral a menos que entre las premisas haya una premisa moral.

A Dworkin se le ha asociado con este tipo de minimalismo de la verdad $^{44} \mathrm{o}$, al menos se piensa que sería desconcertante que lo rechazara. ${ }^{45}$ Sin embargo, puede sostenerse que no lo suscribió. Res-

${ }^{44}$ V. Colman, Jules, op., cit., pp. 54-57; Zipursky, Benjamin, "Two Takes on Truth in Normative Discourse", Boston University Law Review núm. especial Symposium: Fustice for Hedgehogs, A Conference on Ronald Dworkin's Forthcoming Book, vol. 90, núm. 2, 2010, pp, 527,531

${ }^{45} \mathrm{~V}$. Kramer, Matthew, "Working on the Inside ...", cit., p. 122. Coleman, aunque no mantuvo específicamente que Dworkin era un minimalista de la verdad, sí le atri- 
pecto a este cargo afirmó, "aunque, por supuesto, la Parte I [de Fustice for Hedgehogs] es consistente con una teoría minimalista, no expresa una." 46

La segunda observación que quiero realizar se enfoca en una equivocada formulación de la estrategia argumentativa de Dworkin en contra del escepticismo externo del error. Al respecto considérese la reconstrucción que Russ Shafer-Landau, un importante teórico moral, ha formulado:

(1) Las afirmaciones no evaluativas, por sí mismas, son incapaces de justificar alguna afirmación moral.

(2) Si las afirmaciones no evaluativas, por sí mismas, son incapaces de justificar alguna afirmación moral, entonces son incapaces, por sí mismas, de obstaculizar [undermining] alguna afirmación moral.

(3) Por tanto, las afirmaciones no evaluativas, por sí mismas, son incapaces de obstaculizar alguna afirmación moral.

(4) Si las afirmaciones no evaluativas, por sí mismas, son incapaces de obstaculizar alguna afirmación moral, entonces todas las formas de escepticismo externo son falsas.

(5) Por tanto, todas las formas de escepticismo externo son falsas. ${ }^{47}$

Este razonamiento está dirigido en contra de todo el escepticismo externo y lo interesante de él es que no sólo contiene a la Ley de Hume entre sus premisas: la proposición (1). Contiene también la extensión de le Ley de Hume: la proposición (3). El atractivo de

buyo una postura deflacionaria de la verdad, basado en su supuesta postura deflacionaria de la objetividad, v. op., cit., pp. 54-55.

${ }^{46}$ Dworkin, Ronald, "Response", Boston University Law Review núm. especial Symposium: Fustice for Hedgehogs, A Conference on Ronald Dworkin's Forthcoming Book, vol. 90, núm. 2, 2010, p. 1064; la traducción es mía. V. también fustice for ..., cit., cap. 3, n. 12. La postura de Dworkin sobre la verdad en la moral (así como en el derecho) es sustantiva, v. ibidem, pp. 172-178 [trad. esp.: 2014, pp. 215-223].

${ }^{4}$ Shafer-Landau, Russ, "Truth and Metaethics", Boston University Law Review núm. especial Symposium: Fustice for Hedgehogs, A Conference on Ronald Dworkin's Forthcoming Book, vol. 90, núm. 2,2010, p. 484; la traducción es mía. esta reconstrucción es que el razonamiento, de ser sólido, implicaría que los escépticos externos se encuentran en un dilema: o bien, al argumentar en contra de las verdades morales, presupondrían subrepticiamente afirmaciones evaluativas (autofrustrándose); o bien, contradirían la Ley de Hume. ${ }^{4}$

La proposición (2) es la más importante y controvertida del razonamiento porque establece el vínculo entre la Ley de Hume y su extensión. Russ Shafer-Landau y Daniel Star observan su importancia y pretenden falsar la proposición mediante contraejemplos. Estos últimos son discutibles, ${ }^{49}$ pero es más importante destacar que la reconstrucción no expresa el orden y relación que deberían mantener ese conjunto de proposiciones. Dworkin les reclama precisamente esto señalando que su apelación a la Ley de Hume no fue para hacer un argumento independiente en contra del escepticismo externo, sino más bien uno distinto: uno que bajo las suposiciones de que el escepticismo es una postura moral y que obstaculizar una proposición moral equivale a fundamentar la afirmación moral de que ella no es verdadera, encuentra una contradicción entre la Ley de Hume y obstaculizar una proposición moral a partir de hechos no mora-

${ }^{48}$ Ibidem, p. 483.

${ }^{49} \mathrm{El}$ contraejemplo de Shafer-Landau (ibidem, p. 485) indica que el hecho de que él no haya estado en un cierto banco el día que fue robado obstaculiza la afirmación de que es culpable del robo. Daniel Star ("Moral Skepticism For Foxes", Boston University) Law Review núm. especial Symposium: Fustice for Hedgehogs, A Conference on Ronald Dworkin's Forthcoming Book, vol. 90, núm. 2, 2010, p. 502) apunta que al no poder detener un meteorito que amenaza la tierra, no tiene sentido decir que alguien debe detenerlo; de modo que a partir de una premisa descriptiva se puede obstaculizar una proposición moral.

La afirmación de que alguien es culpable requiere de una afirmación que declare las condiciones de culpabilidad y esa afirmación sería evaluativa; y, por lo que respecta al segundo caso, contrario a la opinión de Star, todo indica que el principio "debe implica puede" es una premisa moral. De modo que no es suficiente que Shafer-Landau no hava estado en el banco el día del robo para no ser culpable; ni tampoco lo es que alguien no pueda detener un meteorito para que no deba detenerlo. 
les. ${ }^{50}$ Esto significa, en primer lugar, que el razonamiento de Dworkin no parte de las proposiciones (1) y (2) para concluir la proposición (3); y, en segundo lugar, que la proposición (5) no es una conclusión que Dworkin haya deducido de las proposiciones (3) y (4). ${ }^{51}$

En gran medida, la proposición (3), es decir, la extensión de la Ley de Hume es una de las conclusiones más importantes de la discusión que Dworkin emprende en contra del escepticismo externo y no la obtiene simplemente de la proposición (1) (la Ley de Hume) y una proposición de enlace como lo es la (2). Desde mi punto de vista la deduce del razonamiento siguiente:

(i) Existe una interpretación moral de las proposiciones que obstaculizan la verdad moral.

(ii) Sólo el escepticismo externo podría proporcionarnos una interpretación no moral de las proposiciones que obstaculizan la verdad moral.

(iii) Todas las formas de escepticismo externo son falsas (proposición (5)).

(iv) Por tanto, sólo existe la interpretación moral de las proposiciones que obstaculizan la verdad moral.

(v) Por tanto, todas las proposiciones que obstaculizan la verdad moral son proposiciones morales.

(vi) Las afirmaciones no evaluativas, por sí mismas, son incapaces de justificar alguna afirmación moral (proposición (1) o Ley de Hume).

(vii) Por tanto, "[l] os desafíos filosóficos a la verdad de los juicios morales [las teorías escépticas de la moral] son en sí mismos

${ }^{50}$ V. Dworkin, Ronald, "Response", cit., pp. 1060-1061; fustice for ..., cit., p. 45 [trad. esp. 2014, p. 66].

${ }^{51}$ Ya que la afirmación de que todo escepticismo es una postura moral implica la proposición (5), todo parece indicar que más bien la estrategia de Dworkin fue fundar la proposición (3) en la proposición (5): todas las formas del escepticismo externo son falsas. Es decir, en gran medida del modo invertido a como Shafer-Landau lo interpreta. teorías morales sustantivas" ${ }^{152} \mathrm{y}$, asimismo, las afirmaciones no evaluativas, por sí mismas, son incapaces de obstaculizar alguna afirmación moral (proposición (3) o extensión de la Ley de Hume).

De ser ésta la reconstrucción adecuada, se observa que no es la proposición (3) de Shafer-Landau la que funda la falsedad del escepticismo externo, ni tampoco sería adecuado utilizarla para fundar la tesis de que las proposiciones que obstaculizan la verdad moral son proposiciones morales. Al contrario, son estas últimas tesis las que fundan tanto la segunda afirmación de Dworkin sobre la objetividad interna, como la proposición (3) de la reconstrucción de Shafer-Landau.

El razonamiento de trasfondo es el siguiente. Debido a que las formas simples de obstaculizar juicios morales (permisión e indeterminación simple) no logran ser neutrales, si acaso hay una interpretación no moral de hacer lo primero, ésta tendría que provenir de una teoría que muestre una forma realmente neutral de efectuarlo. Este desafío sólo podría ser satisfecho sosteniendo algún tipo de escepticismo externo; es decir, uno que muestre que podemos decir que los juicios morales no son verdaderos ni falsos en un sentido que no contengan implicaciones directas para la acción (es decir, que ni siquiera contengan juicios morales teóricos ni contrafácticos). La pregunta relevante es entonces la que se había anunciado: ¿existe algún escepticismo externo que logre esa obstaculización de los juicios morales a la vez que sea neutral?

De tener una respuesta negativa a esta pregunta se seguirá que las únicas dos maneras de rechazar los juicios morales son las que Dworkin describe como no neutrales (permisión e indeterminación simple) y ello probará las premisas (iv) y (v) de mi reconstrucción de su razonamiento. Veamos con algún detalle este tipo de respuesta.

\footnotetext{
${ }^{52}$ Dworkin, Ronald, fustice for ..., cit., p. 34 [trad. esp.: 2014, p. 54].
} 


\section{El rechazo del escepticismo externo de estatus}

El escepticismo externo de estatus niega la capacidad de los juicios morales para ser verdaderos o falsos porque, según su explicación, el estatus de los juicios morales no es descriptivo. En su lugar, mantiene que los superficialmente juicios morales son expresiones de actitud, mandatos disfrazados, etc. Este escepticismo se sostiene bajo la premisa de que hay un lenguaje no moral (un lenguaje moralmente austero) que nos permite hablar del lenguaje moral. Dworkin considera dos versiones. La primera mantiene que hay una distinción entre el lenguaje moral y la metaética (un lenguaje de segundo orden que nos dice qué aptitud tiene el lenguaje moral). En el nivel moral mantenemos juicios como, por ejemplo, que el aborto es incorrecto, que el matrimonio entre personas del mismo sexo debe ser autorizado legalmente, etc. En el nivel metaético, en cambio, afirmamos qué tipo de juicios son esos. El escéptico de estatus mantiene en particular que son expresiones de actitud, prescripciones, etc., pero no afirmaciones susceptibles de ser verdaderas o falsas.

La segunda versión de este escepticismo afirma que hay una distinción entre el discurso moral de uso común y el filosófico. En lugar de dos niveles del lenguaje, mantiene que hay dos juegos del lenguaje. Mientras en un juego lingüístico (el lenguaje de uso común) hacemos juicios morales e incluso los declaramos como verdaderos u objetivos; en el otro (el filosófico) los rechazamos como tales, atribuyéndoles el carácter de proyecciones de actitud. ${ }^{53}$ Una analogía útil se encuentra en el lenguaje ficticio. Podríamos decir que muchas afirmaciones son verdaderas en el mundo ficticio, pero no así, en el mundo real. Usando un lenguaje sobre el mundo ficticio decimos que Batman usa capucha y podemos agregar incluso que es verdadero; pero, usando el lenguaje de la realidad mantenemos que más bien se trata de una invención.

${ }^{53}$ Se trata de una versión cuyos fundamentos Dworkin encuentra en Rorty, Richard, "Does Academic Freedom Have Philosophical Presuppositions?", Academe, vol. 80, núm. 6, 1994, pp. 52-63.
Dworkin discute este tipo de escepticismo erigiendo preguntas como la siguiente: “ipor qué no es el escepticismo del estatus la mera proyección de la actitud opuesta y de ningún modo una posición filosófica?" ${ }^{54} \mathrm{Si}$ los escépticos de estatus basados en metaética dicen que frases que superficialmente figuran como juicios morales son en realidad expresiones de actitud, ¿por qué no también su propuesta escéptica está sujeta al mismo tipo de cuestionamiento sobre su estatus? Del mismo modo ocurre con los escépticos de estatus del discurso filosófico. Si dicen que los juicios de la realidad moral del lenguaje de uso común no son, en el lenguaje filosófico de la "verdadera realidad moral", verdaderos, ¿por qué no esta propuesta escéptica es también una propuesta del lenguaje de uso común? ${ }^{55}$

Pero al margen de esas preguntas provocativas, su rechazo del escepticismo de estatus se basa en una postura afirmativa; mantiene que la tesis de que las afirmaciones metaéticas o filosóficas sobre la moral carecen de cualquier significado distinto a uno moral. ${ }^{56} \mathrm{Al}$ respecto discute pormenorizadamente varias de las supuestas afirmaciones metaéticas o filosóficas del escepticismo de estatus llegando a la conclusión de que son morales..$^{57}$

${ }^{54}$ V. Dworkin, Ronald, fustice for ..., cit., p. 52 [trad. esp.: 2014, p. 74].

${ }_{55}$ Para un dilema del escéptico de estatus asociado con este tipo de cuestionamiento, v. Iglesias Vila, Marisa, Facing fudicial Discretion: Legal Knowledge and Right Answers Revisited, Dordrechts, Kluwer Academic Publishers, 2001, p. 121, n. 47.

${ }^{6}$ Leiter ha enfatizado correctamente que en el debate de la objetividad moral se deben descartar las estipulaciones, v. op., cit., pp. 232-233 [trad. esp.: 2012, pp. 301 $302]$. Se ha destacado también la trivialidad de cualquier estipulación al respecto: "Nada en los argumentos - a favor o en contra del realismo, sea robusto o del que sea- parece depender del uso de la palabra 'metanormativo' en lugar de 'normativo' para describirlos", Enoch, David, Taking Morality Seriously, Oxford, Oxford University Press, 2011, p. 130; la traducción es mía.

${ }^{57}$ V. Dworkin, Ronald, “Objectivity ...”, cit., pp. 99-112 [trad. esp.: 2009, pp. 3351]. Dworkin mantiene que la tesis de la objetividad moral es interna, no por estipulación, sino como el resultado de su discusión en contra del escepticismo externo. 
Para ilustrar este tipo de estrategia refutatoria, considérese algunas de las supuestas afirmaciones metaéticas realistas como "realmente hay propiedades o hechos en el universo que son objetivos y morales" o "realmente la esclavitud es incorrecta". Podemos cuestionar la verdad de estas afirmaciones y llegar a conclusiones escépticas: "no hay realmente propiedades o hechos en el universo que sean objetivos y morales"; o, "la esclavitud no es realmente incorrecta". Sin embargo, también podemos hacer otro tipo de cuestionamiento sobre dichas afirmaciones: el de su naturaleza. Es decir, en lugar de preguntarnos si realmente existen o no los hechos o propiedades morales, podemos preguntarnos qué tipo de afirmaciones son esas; si se trata de afirmaciones metafísicas como podría parecer, o si, en cambio, se trata de afirmaciones morales encubiertas. Mediante este tipo de cuestionamiento, independientemente de nuestro acuerdo o desacuerdo con las afirmaciones realistas de que hay propiedades o hechos en el universo que son objetivos y morales, o de que realmente la esclavitud es incorrecta, podemos disentir sobre la naturaleza de dichas afirmaciones. Dworkin se apoya en este tipo de debate y llega a la conclusión de que las afirmaciones sobre la existencia o no de hechos y propiedades morales solamente pueden ser interpretadas como afirmaciones morales. ${ }^{58}$

${ }^{58}$ Como se habrá observado, Dworkin está revirtiendo precisamente la estrategia de los escépticos del estatus en contra de ellos mismos. Mientras estos últimos pretenden discutir la naturaleza de los juicios morales; el primero hace lo mismo, pero sobre la naturaleza de las afirmaciones nominalmente metafisicas (en este caso realistas). La gran diferencia será que Dworkin considera que su discusión sobre la naturaleza de los juicios morales es una discusión moral, no metafísica. Por ello no tiene reparo en conceder el realismo moral: "Declaran [los realistas morales] que realmente hay propiedades o hechos en el universo que son objetivos y normativos, lo cual es verdadero", "Objectivity ...", cit., p. 127 [trad. esp.: 2009, p. 73]. Les discute, en cambio, su opinión sobre la naturaleza de dicho juicio realista: "Pero lo expresan en un lenguaje que se esfuerza por resonar metafísicamente, como si su verdad fuera a descubrirse en algún dominio filosófico distinto al de la evaluación sustantiva", idem. Se ha etiquetado esta postura como un "realismo relajado", al respecto, v. McGrath, op., cit., p. 187, 196 et passim.
El que las afirmaciones sobre la existencia de hechos morales puedan ser interpretadas como afirmaciones morales parece claro. Por ejemplo, la afirmación de que la incorrección del aborto es un hecho que ocurre allá afuera en un reino moral subsistente e independiente, puede entenderse como una metafórica e inflada manera de decir la afirmación moral de que la incorrección del aborto no depende de que alguien lo piense así. ${ }^{59}$ Sin embargo, el que aquellas afirmaciones sólo puedan ser interpretadas de manera moral incorpora más dificultadas. Todo indica que en la defensa de esta tesis nuevamente está implícita la Ley de Hume.

Recordemos que Hume afirmó que ningún conjunto de enunciados descriptivos puede implicar alguno moral. Como se ha señalado, esta Ley le pareció patentemente verdadera a Dworkin y ahora se apoya en ella para afirmar que la moral se encuentra independizada de la metafísica, ${ }^{60}$ de modo que si supuestas afirmaciones metafísicas tienen consecuencias morales esto no puede ser por otra razón sino porque en realidad las primeras son morales ${ }^{61}$ Ya se ha visto esta estrategia en acción al considerar las afirmaciones de permisión e indeterminación simple. Estas afirmaciones implican juicios morales teóricos o contrafácticos y, por ende, tienen que ser morales. Ahora la pregunta es por las afirmaciones metafísicas sobre el estatus de la moral y que pueden dar lugar a algún tipo de indeterminación externa de la moral.

${ }^{59}$ V. Dworkin, Ronald, "Objectivity ...”, cit., p. 99 [trad. esp.: 2009, p. 33].

${ }^{60}$ Considerando que la moral es una sección del dominio evaluativo, se puede afirmar que para Dworkin la independencia metafisica de la moral fue parte de una de las tesis principales de fustice for Hedgehogs: "Debo ahora resumir lo que podría parecer el punto de vista más radical que defiendo: la independencia metafísica del valor", p. 9 [trad. esp.: 2014, p. 24].

${ }^{61}$ De conformidad con esto, se ha entendido que para Dworkin las afirmaciones metaéticas que analiza tienen implicaciones éticas, lo cual hace que las aparentemente teorías metaéticas sean teorías normativas (v., e.g., McPherson, Tristram, "Metaethics and the Autonomy of Morality", Philosophers' Imprint, vol. 8, núm. 6, 2008, p. 5; Enoch, op., cit., p. 129, n. 98). Como se ha mencionado, todo indica que es la Ley de Hume la que sustenta la teoría de Dworkin. 
Comencemos por examinar las típicas afirmaciones supuestamente metafísicas, i.e., las afirmaciones de existencia de hechos morales. Si estas afirmaciones implican por sí mismas juicios morales, tendremos una prueba clara de que no pueden ser metafísicas, sino morales. Considérese entonces nuevamente la afirmación de que hay propiedades o hechos morales en el universo. ¿Podría tener algún sentido metafísico? La respuesta es negativa y esto se debe a que "es u ocasiona un rechazo general del escepticismo interno global: pretende que algunos actos realmente son injustos, o que algunas personas son realmente buenas, o algo de esa especie." ${ }_{62}$ Es decir, las afirmaciones de esa clase tienen implicaciones morales directas y por la Ley de Hume tienen que ser morales.

¿Las negaciones antirrealistas conllevan el mismo destino? Dworkin afirma que sí. Una negación antirrealista, por ejemplo, que la esclavitud no es realmente incorrecta o, en general, que no hay realmente actos buenos ni malos, supone algún tipo de juicio moral teórico o contrafáctico, como el de que los actos son buenos o malos dependiendo de cómo lo pensemos o de las actitudes que tengamos. ${ }^{63}$ Así, nuevamente la Ley de Hume conduce a que tales afirmaciones, supuestamente obstaculizadoras externas de la moral, en realidad tienen que ser morales. En síntesis, el debate realismo/antirrealismo, no es un debate metafísico; es uno moral. Y de manera paralela también lo es el debate objetividad/escepticismo. ${ }^{64}$

${ }^{62}$ Dworkin, Ronald, “Objectivity ...”, cit., p. 100 [trad. esp.: 2009, p. 35].

${ }^{63} V$. también Street, Sharon, op., cit., pp. 303-304.

${ }^{64}$ Otra reconstrucción sostiene que más bien se trata de un debate de afirmaciones morales directas, $v$. Bloomfield, Paul, "Archimedeanism and Why Metaethics Matters", en Russ Shafer-Landau (ed.), Oxford Studies in Metaethics, vol. IV, Oxford, Oxford University Press, 2009, pp. 288-289; Marti, Jose Luis y Hugo Omar Seleme, op., cit., pp. 4-6. Por otra parte, se ha sostenido que la argumentación de Dworkin sólo posee fuerza inductiva y, por ende, está sujeta a objeciones de insuficiencia, $c f r$. Star, Daniel, "Moral Skepticism For Foxes", Boston University Law Review núm. especial Symposium: Fustice for Hedgehogs, A Conference on Ronald Dworkin's Forthcoming Book, vol. 90, núm. 2, 2010, p. 502; Enoch, op., cit., p. 130. Para una conocida objeción en contra

\section{EL RECHAZO DEL ESCEPTICISMO EXTERNO DEL ERROR}

El escepticismo externo del error también es austero al recurrir sólo a argumentos o afirmaciones metaéticas para negar los juicios morales. John Mackie consideró que la realidad no contenía valores morales y que en virtud de ello todos los juicios morales eran falsos. ${ }^{65}$ Como ya se ha mencionado, a diferencia del escepticismo del estatus, el del error no es neutral en el sentido en el que Dworkin comprende ese concepto. El escepticismo del error únicamente recurre a las dos formas que Dworkin señala como comunes para negar los juicios morales: falsedad e indeterminación simple; y, desde ese punto de vista, su teoría no deja de mantener las consecuencias directas para la acción que tienen dichos juicios. No obstante, aún sin neutralidad, debido a su austeridad el escepticismo externo del error objeta la teoría de la objetividad moral interna porque no deja de implicar que para la verdad de un juicio moral no es suficiente la argumentación moral adecuada.

Este tipo de teoría puede ser objetada sin tener que ir demasiado lejos por una falla inicial: en realidad le falta austeridad. Esta falla se debe a que podría estar suponiendo un juicio moral teórico o contrafáctico para deducir sus conclusiones escépticas; por ejemplo, podría suponer que si hubiera propiedades o hechos morales habría verdad moral, pero que no existen esos hacedores de verdad. Si ese fuera el caso, entonces sería una teoría escéptica, pero interna. Esto se debe a que la base de su escepticismo no puede ser un mero conjunto de afirmaciones descriptivas; ya contiene una evaluativa,

de la conclusión de Dworkin (y a favor de la posibilidad de una auténtica neutralidad metaética), v. Dreier, James, "Meta-ethics and Normative Commitment", Philosophical Issues, núm. 12, 2002, pp. 241-263. Para una respuesta a Dreier y la consideración de un argumento distinto al de Dworkin a favor de la tesis de que no hay posturas metaéticas moralmente neutrales, $v$. Fantl, Jeremy, "Is Metaethics Moraly Neutral?", Pacific Philosophical Quarterly, núm. 87, 2006, pp. 24-44.

${ }^{65}$ V. op., cit., cap. I. 
a saber, el juicio moral contrafáctico que funda su escepticismo. ${ }^{66}$

Para beneficio del escepticismo externo del error, podemos suponer que puede evitar esa equivocación inicial logrando evadir ese tipo de juicios morales contrafácticos simplemente aportando argumentos externos sobre una estructura de la realidad que impide la verdad moral. ${ }^{67}$ A continuación consideraré 6 versiones de esta teoría:

a) Todos los juicios morales son falsos.

b) Todos los juicios morales son indeterminados.

c) Todos los juicios morales positivos son falsos.

d) Todos los juicios morales positivos son indeterminados.

e) Todos los juicios morales atómicos no negativos son falsos.

f) Todos los juicios morales atómicos no negativos son indeterminados.

Sin explicar con detalle todos estos tipos de escepticismo externo del error, Dworkin réplica generalizadamente cualquiera de sus versiones a través de dos estrategias. Una de ellas consiste en la refutación de cada uno de los argumentos que podría sostener tal escepticismo externo. ${ }^{68}$ La otra es una objeción por inconsistencia.

${ }^{66}$ Hanin (op., cit.) ha argumentado, en contra del escepticismo del error, que no puede evadir ese tipo de suposiciones salvo cometiendo una petición de principio, violar la ley de Hume o implicar una contradicción. Kramer (Moral Realism ..., cit., pp. 6, 106) es otro objetor que, apoyándose en la Ley de Hume, parece entender el escepticismo externo del error de este modo y concluye que es incoherente dado que para mantener su conclusión escéptica total ha de basarse en un argumento moral.

${ }^{67}$ Dworkin objeta que una teoría escéptica que suponga un juicio moral teórico o contrafáctico no puede ser externa, v. "Objectivity ...", cit., p. 113 [trad. esp.: 2009, p. 52]; Fustice for ..., cit., pp. 46-47 [trad. esp.: 2014, pp. 67-68]. Concibe, sin embargo, la posibilidad de que se pretenda evadir tal suposición como punto de partida de un escéptico del error, v. "Objectivity ...", cit., p. 113 [trad. esp.: 2009, p. 52]; fustice for ..., cit., pp. 32 [trad. esp.: 2014, p. 51]. Lo que resta de esta sección tiene el propósito de discutir tal posibilidad.

${ }^{68}$ No me detendré en este punto porque excedería los límites de este trabajo. Para los detalles argumentativos, v. Dworkin, Ronald, "Objectivity ..., cit., pp. 112-116 [trad. esp.: 2009, pp. 52-57]; fustice for ..., cit., pp. 47-51 [trad. esp.: 2014, pp. 68-73].
Esta última objeción se encuentra sintetizada en el pasaje siguiente:

Si el escepticismo externo [del estatus o del error] es en sí mismo una postura moral, entonces se contradice. El escepticismo externo del error parece más inmediatamente vulnerable porque sostiene que todas las afirmaciones morales son falsas. Los escépticos del error tal vez revisaran su opinión, empero, para sostener que solo son falsos todos los juicios morales positivos. Podrían decir que los juicios morales positivos son los que proponen una guía para la acción o la aprobación [...]. Podrían denominar juicios morales negativos las alternativas a esas afirmaciones: que una determinada situación no es buena ni mala sino moralmente neutra [...]. Pero, como dije antes, estos siguen siendo juicios morales [...]. Así revisado, el escepticismo del error sería en consecuencia un ejemplo de escepticismo interno global. Tendría el mismo contenido, pongamos por caso, que la teoría de que Dios es el único autor posible del deber moral y no existe. Un escéptico del error quizá tenga la esperanza de apoyarse en algún argumento paralelo a ese: que solo las entidades peculiares pueden imponer deberes morales y que no hay entidades peculiares. ${ }^{69}$

Se pueden extender las razones que aporta Dworkin en este pasaje para exponer inconsistencias en las 6 versiones del escepticismo del error que he presentado.

La versión a) es objetable fácilmente porque de ser falsos todos los juicios morales habría una clara contradicción. Supóngase, por ejemplo, que son falsos todos los juicios que afirman un deber. De ello se sigue que son verdaderos los juicios que permiten las acciones contrarias a esos deberes. Estos últimos son juicios morales. En consecuencia, hay juicios morales verdaderos, lo cual contradice la hipótesis de la que partimos.

Supóngase que alguien agrega que justamente la versión mantiene que también son falsos todos los juicios morales permisivos. Por ejemplo, que es falso tanto el juicio que reclama ayudar a los indi-

${ }^{69}$ Ibidem, pp. 46-47 [trad. esp.: 2014, pp. 67-68] 
gentes como aquel que permite no ayudarlos. Se seguirá entonces que es verdadero tanto que se puede deónticamente no ayudar a los indigentes como que se debe ayudarlos: ${ }^{70}$ lo cual significa nuevamente mantener juicios morales verdaderos; ahora contradictorios. De modo que esta versión no puede evitar ser inconsistente. ${ }^{71}$

La versión b) rechaza todos los juicios morales, pero no a través de declaraciones de falsedad, sino solamente a través de juicios de indeterminación. Estos se conforman de juicios que simplemente niegan la verdad moral (en ocasiones también equiparado a negar que sea el caso). Por ejemplo, si consideramos el juicio moral de que el aborto está prohibido, éste se puede rechazar enunciando: "no es verdad que el aborto esté prohibido." ${ }^{2}$ Esta manera de rechazar los juicios morales permite que sean consistentes los dos enunciados siguientes:

- No es verdadero que el aborto esté prohibido.

- No es verdadero que el aborto esté permitido. ${ }^{73}$

${ }^{70}$ Para inferir esto me apoyo en la clásica interdefinibilidad de los operadores deónticos, i.e.: i) una prohibición equivale a una obligación de no hacer $(\operatorname{Php} \leftrightarrow \mathrm{O} \sim \mathrm{p})$; ii) la negación de una obligación equivale a una permisión de no hacer $(\sim \mathrm{Op} \leftrightarrow \mathrm{P} \sim \mathrm{p})$; y, iii) la negación de una permisión de hacer equivale a una obligación de no hacer $(\sim \mathrm{Pp} \leftrightarrow \mathrm{O} \sim \mathrm{p})$.

${ }^{71}$ Recientemente Kramer ("There's Nothing ..." cit., pp. 4-5) ha destacado, como posible defensa de la teoría de Mackie, la interpretación de que ésta no niega los juicios morales permisivos. Argumenta que lo que este autor consideraba inconsistente era la objetividad con las propiedades prescriptivas, pero que la permisividad no era una propiedad moral prescriptiva; de modo que, sugerentemente, la permisividad de una conducta es consistente con los argumentos escépticos. Shafer-Landau (op., cit., pp. 490-491) ha considerado que el escéptico podría fácilmente recurrir a este tipo de réplica en contra de los argumentos de Dworkin. En breve objetaré otras versiones del escepticismo del error que también responden a estas lecturas.

${ }^{72}$ Esta es la interpretación que, por ejemplo, se considera en Shafer-Landau, Russ, op., cit., pp. 490-491.

${ }^{73}$ Algunos autores han considerado que Dworkin rechazó esta posibilidad lógica. Argumentan que mantenía la implicación de enunciados como "No es el caso que x esté prohibido" a "Está permitido no x"; así como la implicación de enunciados como
La conjunción de estos dos juicios conforma un juicio de indeterminación moral. De manera que podría parecer que el escepticismo del error finalmente sí puede, de algún modo, rechazar todos los juicios morales. Sin embargo, debido a que los juicios a través de los cuales establecería su escepticismo serían los de indeterminación simple, se sigue que no puede rechazar todos los juicios morales porque estos últimos también son morales. De modo que esta versión tampoco puede ser consistente.

Las versiones c), d), e) y f) restringen los alcances de su escepticismo para evitar alguna inconsistencia en el contenido que afirman. Del pasaje de Dworkin se advierte un argumento por el que la versión c) no puede ser una afirmación que sostenga el escepticismo externo. Ahí se sugieren dos razones de ello: o bien, simplemente porque se mantendrían juicios morales verdaderos (al menos los negativos); o bien, porque se acabaría manteniendo un juicio moral contrafáctico para apoyar el contenido moral negativo que asegura tal escepticismo. En cualquiera de estos dos casos, independientemente de que se incurra o no en una autocontradicción como la que implican las versiones a) y b), el escepticismo sólo podría ser interno. Existe, sin embargo, otro tipo de contradicción en ello, pero ahora surge en la afirmación de que el contenido del escepticismo externo es aquel que declara la versión c).

La extensión de estas razones a las otras tres versiones del escepticismo del error tiene la misma consecuencia: se trata de versiones

"No es el caso que x está permitido" a "Está prohibido x", v. Pigden, Charles, "Nihilism, Nietzsche and the Doppelganger Problem", Ethical Theory and Moral Practice, vol. 10, núm. 5, 2007, pp. 441-456; Olson, Jonas, "In Defense of Moral Error Theory", en Michael Brady (ed.), New Waves in Metaethics, Basingstoke, Palgrave Macmillan, 2010, pp. 62-84. Estas implicaciones serían suficientes para hacer autocontradictoria a la teoría del error. Asiento con Hanin (op., cit., pp. 360-64) en que Dworkin no rechaza esa posibilidad lógica. Los juicios de indeterminación la requieren, $v$. Dworkin, Ronald, fustice for ..., cit., p. 44 [trad. esp.: 2014, p. 65]. Como se observará de inmediato, no se requieren esas implicaciones para mostrar que hay una contradicción en la versión b). 
de escepticismo interno, que independientemente de si su contenido es posible, es inconsistente declararlo como el contenido de una versión de escepticismo externo. Analizaré esto con detalle nuevamente a partir de la versión c).

De acuerdo con la versión c), todos los juicios morales positivos son falsos. Como la falsedad de todos los juicios morales positivos implica, al menos, juicios morales negativos; digamos, juicios simples de indeterminación moral, se sigue que no pueden ser falsos todos los juicios morales. Por sí mismo, esto no señala que el contenido de este escepticismo sea imposible, ${ }^{74}$ pero los juicios morales que se tienen que afirmar para sostener esta versión del escepticismo, aunque negativos, están sujetos a la Ley de Hume y sólo podrían ser deducidos a partir de una premisa moral, de modo que no puede ser que su fundamento sea exclusivamente una afirmación o conjunto de afirmaciones metafísicas. Su fundamentación requiere una premisa moral que impide que eso sea escepticismo externo. Es, por tanto, contradictorio afirmar que esta sea una versión de escepticismo externo del error. ${ }^{75}$

La versión d) sostiene la indeterminación de todos los juicios morales positivos; y, por la manera como analicé la versión c), estaría sujeta exactamente a la misma objeción. ${ }^{76}$

${ }^{74} \mathrm{La}$ falsedad de todos los juicios morales positivos implica, desde otro punto de vista, una contradicción. Más allá de lo que Dworkin observa, incluso la versión c) es un escepticismo de contenido imposible, de la misma manera como lo son las versiones a) y b). En la exposición ignoro este aspecto para dar cuenta del alcance de la crítica de Dworkin.

${ }^{75}$ Vale la pena agregar que si el juicio moral que fundamenta los juicios morales negativos que afirma esta versión es contrafáctico, se sigue que esta teoría además mantiene un contenido imposible: como un juicio moral contrafáctico es positivo, se estaría afirmando a la vez que falsando.

${ }^{76}$ De manera parecida a como se explicó en la nota inmediata anterior, si el juicio moral que fundamenta los juicios morales negativos que afirma ahora esta versión es contrafáctico, se sigue que esta teoría además mantiene un contenido ahora inexplicable: como un juicio moral contrafáctico es positivo, se estaría afirmando a la vez que declarando su indeterminación. ¿Es esto posible?
La versión e), mantiene que "todas las proposiciones morales atómicas no negativas son falsas." 77 Esta afirmación es compatible con la verdad de proposiciones morales no atómicas o negativas. Pero de poco le sirve ello. Del pasaje de Dworkin aún se puede extraer una refutación en contra de esta versión. Si interpretamos que las proposiciones permisivas no son atómicas (o, en su caso, que son negativas), la versión estaría manteniendo que todas las proposiciones morales que obligan o prohíben son falsas, y de ello se seguiría que todo está moralmente permitido, ocurriendo que las proposiciones que lo declaren son morales. Este tipo de escepticismo tampoco es total: ${ }^{78}$ pero aún supone ser externo. Sin embargo, no puede ser esto último porque la Ley de Hume exige que la deducción de las proposiciones morales permisivas parta de alguna premisa moral y si fuera externo no habría premisas morales de las cuales hacer tal deducción. Por otra parte, si alguien agrega que incluso las proposiciones morales permisivas de algún modo son atómicas no negativas, entonces implica una inconsistencia en su contenido, porque declararía la falsedad de todas las proposiciones de deber y de todas las permisivas.

Finalmente, la versión f), mantiene la indeterminación de todos los juicios morales atómicos no negativos. Esta versión tiene su atractivo al ser consistente en mantener la indeterminación de todos los juicios de obligación (y por ende de los de permisión) del ámbito moral; sin declarar lo mismo acerca de los mismos juicios

\footnotetext{
${ }^{77}$ Pigden, Charles, op., cit., p. 451; la traducción es mía.

${ }^{78}$ Kramer mantiene que no es ni siquiera un escepticismo global: "En la medida en que Dworkin se propone relatar una postura extendidamente adoptada, erra al designarla como una variedad de escepticismo. No es ni siquiera una variedad de escepticismo altamente restringido", Kramer. Matthew, "Working on the Inside ...", cit., p. 119; la traducción es mía. Esta podría ser la razón por la que Smith y Star rechazan interpretar al escepticismo externo del error de aquella manera, $v$. Smith, Michael, "Dworkin on External Skepticism", Boston University Law Review núm. especial Symposium: fustice for Hedgehogs, A Conference on Ronald Dworkin's Forthcoming Book, vol. 90, núm. 2, 2010, p. 512; Star, Daniel, op., cit., pp. 500-501.
} 
de indeterminación ni de los juicios morales contrafácticos. Los primeros escapan de su alcance escéptico porque son juicios negativos y los segundos porque no son atómicos. Sin embargo, las afirmaciones de Dworkin nuevamente son suficientes para la refutación de la versión. Debido a que los juicios de indeterminación moral son juicios morales, la Ley de Hume los rige y pide un juicio moral para su deducción. Ese juicio moral puede ser uno contrafáctico, pero no importa si no lo es, porque aun cuando fuera de otro tipo, se debe tratar de un juicio moral y por ello la versión no puede ser austera.

En síntesis, de conformidad con esta sección del artículo, el escepticismo externo del error es una teoría equivocada y, de conformidad con la anterior, el escepticismo externo de estatus también lo es. De no existir más formas de escepticismo externo, entonces la extensión de la Ley de Hume sería verdadera, esto es, cualquier manera de obstaculizar un juicio moral tiene incluir otro juicio moral. Ésta sería la garantía que otorga seriedad a la teoría de la objetividad interna en el ámbito moral porque, si bien a través de la Ley de Hume podemos afirmar que la argumentación evaluativa adecuada es una condición necesaria para la verdad de toda proposición evaluativa, con la extensión de la Ley de Hume podemos afirmar que la argumentación evaluativa adecuada es condición suficiente para la verdad de toda proposición evaluativa. Si esto es así, el único espacio para el escepticismo es el interno y éste no es sino una confirmación de la teoría de la objetividad interna.

IV. LA TEORÍA De LA OBJetividad INTERNA EN EL ÁmBITO JURÍDICO

Todas las explicaciones tratadas en la sección anterior y sus subsecciones son extensibles para explicar la objetividad interna en el ámbito jurídico, simplemente se tienen que elaborar las adaptaciones adecuadas.
La adaptación central ocurre en el espacio conceptual de la objetividad jurídica interna. Dicho espacio es el siguiente: todas las verdades jurídicas se mantienen con independencia de las creencias y actitudes de la gente, pero sus fundamentos no son meramente hechos naturales, ni supuestos hechos jurídicos o evaluativos de algún tipo, sino la argumentación jurídica adecuada. ${ }^{79}$

Así, como en el ámbito moral, una afirmación de ese tipo se encuentra sustentada en las dos tesis siguientes:

1) Los juicios jurídicos son verdaderos, cuando lo son, por obra de un argumento jurídico adecuado a favor de su verdad; $y$

2) Los desafíos filosóficos a la verdad de los juicios jurídicos [las teorías escépticas del derecho] son en sí mismos teorías evaluativas sustantivas.

La primera de estas tesis se encuentra sustentada en la Ley de Hume. Como los juicios jurídicos son evaluativos, no podríamos fundar ningún juicio jurídico salvo apelando a una afirmación evaluativa introducida en un argumento jurídico.

La segunda, es la extensión de la Ley de Hume en el ámbito jurídico. Afirma que no existe una sola manera de obstaculizar juicios jurídicos, salvo mediante argumentos que contengan premisas evaluativas.

La extensión de la Ley de Hume en el ámbito jurídico depende, como en el ámbito moral, de que se prueben dos afirmaciones: i) que los juicios de indeterminación simple y los permisivos en el ámbito jurídico son jurídicos; y, ii) que el escepticismo externo, en todas sus formas, es falso.

La prueba de la afirmación i) es que los juicios de indeterminación simple y los permisivos del ámbito jurídico, como ocurrió con los morales cuando fueron analizados, presuponen juicios teóricos

${ }^{79}$ En la teoría jurídica de Dworkin la argumentación jurídica adecuada es la mejor argumentación moral del derecho establecido, v. Dworkin, Ronald, Law's ..., cit., caps. 2,3 y 7 . 
o contrafácticos. Piénsese en los juicios de indeterminación jurídica. Nadie podría afirmar, por ejemplo, que no es verdadero ni falso que debemos jurídicamente evitar el autodaño, salvo suponiendo un juicio teórico que, por ofrecer un ejemplo, afirme algo como lo siguiente: para que exista un deber en el ámbito jurídico se necesita que una fuente de derecho lo emane. Un juicio teórico de este tipo es evaluativo. Así, las afirmaciones de indeterminación jurídica, al suponer afirmaciones evaluativas (juicios teóricos evaluativos como el anterior), por la Ley de Hume tienen que ser evaluativas. (Lo mismo ocurre con las afirmaciones permisivas del ámbito jurídico).

La prueba de la afirmación ii) es una argumentación análoga en contra de las formas de escepticismo externo en el ámbito jurídico. Al respecto el lector puede imaginar cómo sería tal argumentación tomando como ejemplo la que fue reconstruida en la sección anterior.

La teoría de la objetividad interna en el ámbito jurídico, como ocurrió con la del ámbito moral, se funda entonces en la Ley de Hume y la extensión de la Ley de Hume.

\section{CONCLUSIONES}

La conclusión principal de este trabajo es que podemos contar con una explicación objetivista interna del derecho, a saber, la que proporciona la teoría de Dworkin. La afirmación central de dicha explicación es la siguiente: todas las verdades jurídicas se mantienen con independencia de las creencias y actitudes de la gente, pero sus fundamentos no son meramente hechos naturales, ni supuestos hechos jurídicos o evaluativos de algún tipo, sino la argumentación jurídica adecuada.

Lo destacable de dicha explicación es que no sólo se funda en la Ley de Hume, sino también en lo que a lo largo del artículo llamé "la extensión de la Ley de Hume". Debido a la credibilidad con la que cuenta la Ley de Hume, si acaso existe alguna debilidad en la teoría de la objetividad interna, sugerentemente ésta debería encontrarse en la extensión de la Ley de Hume.
VI. F UENTES

1. Bibliografía

Alexander, Larry, "Legal Objectivity and the Illusion of Legal Principles", en Matthias Klatt (ed.), Institutionalized Reason: Thefurisprudence of Robert Alexy, Nueva York, Oxford University Press, 2012.

Bloomfield, Paul, "Archimedeanism and Why Metaethics Matters", en Russ Shafer-Landau (ed.), Oxford Studies in Metaethics, vol. IV, Oxford, Oxford University Press, 2009.

Dworkin, Ronald, Law's Empire, Cambridge, Massachusetts, Harvard University Press, 1986

_, El Imperio de la fusticia, 2a. ed., trad. de Claudia Ferrari, Barcelona, Gedisa, 1992

, Fustice in Robes, Cambridge, Massachusetts, Harvard University Press, 2006.

La fusticia con Toga, trad. de Marisa Iglesias y Íñigo Ortíz, Madrid, Marcial Pons, 2007.

, "Objetividad y Verdad, más vale que lo crea", en Edison Otero (comp.), Filósofos Actuales de Habla Inglesa, trad. de Edison Otero, Santiago de Chile, Universidad Diego Portales, 2009

- Fustice for Hedgehogs, Cambridge, Massachusetts, Harvard University Press, 2011.

— Gusticia para Erizos, trad. de Horacio Pons, Ciudad de México, FCE, 2014.

Enoch, David, Taking Morality Seriously, Oxford, Oxford University Press, 2011.

García Sú́rez, Alfonso, Modos de Significar, 2a. ed., Tecnos, Madrid, 2011.

Greenawalt, Kent, Law and Objectivity, Oxford, Oxford University Press, 1992.

Hume, David, A Treatise of Human Nature, edición Selby-Bigge (1789), Oxford, Clarendon Press, 1739-40. 
Tratado de la Naturaleza Humana, trad. de Félix Duque, Madrid, Tecnos, 2005.

Iglesias Vila, Marisa, Facing Fudicial Discretion: Legal Knowledge and Right Answers Revisited, Dordrechts, Kluwer Academic Publishers, 2001.

Joyce, Richard, The Myth of Morality, Cambridge, Cambridge University Press, 2001.

Kramer, Matthew, Objectivity and the Rule of Law, Cambridge, Cambridge University Press, 2007.

_- Moral Realism as a Moral Doctrine, Oxford, Wiley-Blackwell, 2009.

LeIter, Brian, Naturalizing Furisprudence: Essays on American Legal Realism and Naturalism in Legal Philosophy, Oxford, Oxford University Press, 2007.

—- Naturalismo y Teoría del Derecho, trad. de Giovanni Battista, Madrid, Marcial Pons, 2012.

Mackie, John, Ethics: Inventing Right and Wrong, Londres, Penguin Books, 1977.

Marmor, Andrei, Interpretación y Teoría del Derecho, trad. de Marcelo Mendoza, Barcelona, Gedisa, 2001.

McGrath, Sarah, "Relax? Don’t Do It! Why Moral Realism Won't Come Cheap", en Russ Shafer-Landau (ed.), Oxford Studies in Metaethics, vol. 9, Oxford, Oxford University Press, 2014.

Moore, Michael, "Semantics, Metaphysics and Objectivity in the Law", en Geert Keil y Ralf Poscher (eds.), Vagueness and Law, Nueva York, Oxford University Press, 2016.

Olson, Jonas, "In Defense of Moral Error Theory", en Michael Brady (ed.), New Waves in Metaethics, Basingstoke, Palgrave Macmillan, 2010 .

Patterson, Dennis, Law and Truth, Oxford, Oxford University Press, 1996.

RAZ, Joseph, "Notes on Value and Objectivity", en Brian Leiter (ed.), Objectivity in Law and Morals, Cambridge, Cambridge University Press, 2001 .
Schiavello, Aldo, "The Third Theory of Legal Objectivity", en M. Araszkiewicz y J. Savelka (eds.), Coherence: Insight from Philosophy, Furisprudence and Artificial Intelligence, Dordrecht, Springer, 2013.

Stavropoulos, Nicos, Objectivity in Law, Oxford, Oxford University Press, 1996.

Street, Sharon, "Objectivity and Truth: You'd Better Rethink it", en Russ Shafer-Landau (ed.), Oxford Studies in Metaethics, vol. 11, Oxford, Oxford University Press, 2016

2. Hemerografía

Coleman, Jules, "Truth and Objectivity in Law", Legal Theory, vol. 1, núm. 1, 1995.

Coleman, Jules y Brian Leiter, "Determinacy, Objectivity, and Authority", University of Pennsylvania Law Review, núm. 142, 1993.

Cuneo, Terence y Russ Shafer-Landau, "The Moral Fixed Points, New Directions for Moral Nonnaturalism”, Philosophical Studies, núm. 171, 2014.

Dreier, James, "Meta-ethics and Normative Commitment", Philosophical Issues, núm. 12, 2002.

Dworkin, Ronald, "Objectivity and Truth, You'd Better Believe it", Philosophy and Public Affairs, vol. 25, núm. 2, 1996.

—_, "Response", Boston University Law Review núm. especial Symposium: Justice for Hedgehogs, A Conference on Ronald Dworkin's Forthcoming Book, vol. 90, núm. 2, 2010.

Fantl, Jeremy, "Is Metaethics Moraly Neutral?", Pacific Philosophical Quarterly, núm. 87, 2006.

Hanin, Mark, "Ethical Anti-Archimedeanism and Moral Error Theory", fournal of Value Inquiry 47, núm. 4, 2013. 
Kramer, Matthew, "Working on the Inside: Ronald Dworkin's Moral Philosophy", Analysis Reviews, vol. 73, núm. 1, 2013.

, “There's Nothing Quasi About Quasi-Realism: Moral Realism as a Moral Doctrine", University of Cambridge Faculty of Law Research Paper, núm. 42, 2016.

Marti, Jose Luis y Hugo Omar Seleme, "Dworkin on external skepticism and moral permissions", Critical Review of International Social and Political Philosophy, vol. 19, núm. 4, 2016.

MaPherson, Tristram, "Metaethics and the Autonomy of Morality”, Philosophers' Imprint, vol. 8, núm. 6, 2008.

— , "The Interpretive Turn in Modern Theory: A Turn for the Worse?", Stanford Law Review, vol. 41, núm. 4, 1989.

Pigden, Charles, "Nihilism, Nietzsche and the Doppelganger Problem", Ethical Theory and Moral Practice, vol. 10, núm. 5, 2007.

Rorty, Richard, "Does Academic Freedom Have Philosophical Presuppositions?”, Academe, vol. 80, núm. 6, 1994.

Shafer-Landau, Russ, "Truth and Metaethics", Boston University Law Review núm. especial Symposium: Fustice for Hedgehogs, A Conference on Ronald Dworkin's Forthcoming Book, vol. 90, núm. 2, 2010.

Smith, Michael, "Dworkin on External Skepticism", Boston University Law Review núm. especial Symposium: Justice for Hedgehogs, A Conference on Ronald Dworkin's Forthcoming Book, vol. 90, núm. 2, 2010.

STAR, Daniel, "Moral Skepticism For Foxes", Boston University Law Review núm. especial Symposium: Fustice for Hedgehogs, A Conference on Ronald Dworkin's Forthcoming Book, vol. 90, núm. 2, 2010.

Zipursky, Benjamin, "Two Takes on Truth in Normative Discourse", Boston University Law Review núm. especial Symposium: Justice for Hedgehogs, A Conference on Ronald Dworkin's Forthcoming Book, vol. 90, núm. 2, 2010. 